\title{
A Mindful Consumer: Attitude of Eco- Spirituality and Sustainable Consumption Intention
}

\author{
R.M.K.S.Rasanjalee ${ }^{1}$ and V.G.P.Lakshika ${ }^{2}$ \\ ${ }^{1}$ Faculty of Management Studies, Sri Lanka Technological Campus, \\ Padukka, Western Province, Sri Lanka \\ ${ }^{2}$ Department of Marketing Management, University of Sri Jayewardenepura, \\ Nugegoda, Western Province, Sri Lanka
}

\begin{abstract}
Overconsumption being a contemporary global issue sustainable consumption has become an emerging arena of research. To meet the challenge of overconsumption the change in mindset has been recognized as important.In response the present paper attempts in examining the possible factors that can influence individuals to become mindful through which sustainable consumption could be achieved. The study proposes a theoretical explanation of the possible factors that can influence individuals to become mindful through which sustainable consumption can be attained based on the premises of Theory of Planned Behavior and Social Cognitive Theory of Moral Agency. A sample of 378 young educated consumers in the Colombo district was enclosed as a convenience sample using a crosssectional survey. A self-administered questionnaire was used while the data was analyzed using Structural Equation Modelling (SEM) with AMOS. A positive impact from the attitude of eco-spirituality, perceived behavioral control, and subjective norms were observed on sustainable consumption intention while the total influence of the indirect impact from environmental concern and environmental knowledge on sustainable consumption intention was higher with the partial mediation of attitude of ecospirituality. Thus, this study contributes to enhancing the predictive power of Theory of Planned Behavior. Keywords:Mindful Consumer; Sustainable Consumption Intention, Environmental Concern, Environment Knowledge, Attitude of Eco-Spirituality
\end{abstract}

\section{Introduction}

In the middle and higher-income markets, which are the "prime" markets, overconsumption is becoming a customer-centric sustainability concern, indicating that consumers now have adequate disposable money for their discretionary purchasing. There is a steady drop in poverty around the world, causing people to emerge from poverty and boost their consumption levels (Sheth et al., 2011). It was also shown that growing consumption raises environmental concerns and has a detrimental impact on both individual and communal well-being. Sea levels are rising around countries such as Sri Lanka, destroying billions of dollars in property, infrastructure, and the livelihoods of millions of people who reside on the island (Katupotha, 2018). The environment, the economy, and society must all work together to achieve sustainability to solve these problems (Ulluwishewa, 2018). Individual behavior and perspective must alter to address the problem of overconsumption at the individual level, which can be accomplished by developing "mindful consumption" (Sheth et al., 2011). Focusing on the individual level, according to Ulluwishewa (2018), could be an effective strategy.

The Theory of Planned Behavior (TPB; Ajzen, 1985) is a key theoretical approach in the context of sustainable consumption and related behaviors, and it provides a theoretical foundation for this study. Personal elements in the form of moral thought and self-evaluative reactions, moral behavior, and environmental influences operate as interactive determinants of each other, according to Bandura's Social Cognitive Theory (Bandura, 1991). According to Wood and Bandura (1989), an individual's spiritual beliefs serve as the foundation for morality, culminating in moral behavior. Spiritual experiences, according to Pargament (1999), enable a person to transcend his or her narrow self-concept and to exercise genuine empathy with others as well as to assume an all-encompassing perspective. Even though previous studies have used the theory of planned behavior to predict environmental and 
sustainable behavior, spirituality is rarely integrated with the Theory of Planned Behavior to understand its impact on sustainable consumption intentions, revealing its moral aspect.As a result, this study would incorporate the attitude of eco-spirituality (Suganthi, 2020) to the theory of planned behavior rather than the generic variable of attitude, while satisfying the requirement to understand the impact of spirituality on sustainable consumption intention through the lens of Bandura's Social Cognitive Theory of moral agency.

Further, it is also crucial to comprehend why people aren't shifting their consumption habits to be more sustainable. According to Sheth et al., (2011) mindful consumption is defined as "consciousness in thought and behavior about consequences of consumption" (p.27). A "Mindful consumer is aware of the environmental problems and pays more attention to environmentally friendly and green products" (Milne et al., 2019, p.9). It further said that a mindful customer is aware of their actions. In support, Ulluwishewa (2018) claims that even when external variables are present, achieving sustainability is difficult without consumers being aware of and motivated by an internal transformation. As a result, the current study aims to identify the possible individual, behavioral, and situational factors influencing a consumer's mindfulness in achieving sustainable consumption intentions, as well as the mediating role of ecospirituality attitude concerning young educated consumers in Sri Lanka.

\section{Review of Literature}

\subsection{Sustainability and Sustainable Consumption Intention (SCI)}

According to the Brundtland World Commission Report (1987), sustainability is defined as "development that meets the demands of the present generation without jeopardizing future generations' ability to satisfy their own needs". However, given the complexities in sustainability challenges occurring as a result of consumption, it is critical to understand how it connects to sustainability to arrive at a solution, as stated in the study's background.

Sustainable consumption intention is characterized as the "Behaviour which intends to meet the needs of the current generation and benefit the environment without jeopardizing the ability of future generations to satisfy their needs" (Leary, Vann, Mittelstaedt, Murphy, \& Sherry Jr, 2014, p.1954). Consumption becomes overconsumption when it is unacceptable or unaffordable due to its effects on the environment, economy, personal and collective well-being, and so on, according to customer-centric sustainability criteria.
ISSN 2455-6378

2.2 Mindfulness, a Mindful Consumer and Sustainability

According to Gethin (2011), mindfulness is a meditative practice that focuses on improving attention and awareness. According to Brown and Ryan (2003), mindful consumption is an inherent state of consciousness that guides one's consumption practices, making it an ongoing practice. As a result, it would encourage consumers to shift toward sustainable consumption rather than acting blindly and habitually.

Meanwhile, several studies have included mindfulness as an independent variable in the study of sustainable and environmentally responsible behavior (Barber \& Deale, 2014; Brown \&Kasser, 2005; Chatzisarantis\& Hagger, 2007). Despite the fact that previous literature covers understanding what mindful consumption is about (Sheth et al., 2011) and who a mindful consumer might be (Milne et al., 2019), a theoretical underpinning of what factors may influence a consumer to be mindful leading to sustainable consumption intention is scarcely reported.

\subsection{Theories associated with the study}

The Theory of Planned Behavior (TPB) was introduced as a step forward from the Theory of Reasoned Action (TRA). The TRA, which was developed to explain an individual's behavior, states that behavior can be predicted based on the individual's behavioral intention, so the intention is the TRA's central concept. The theory's underlying assumption is that intention is a direct predictor of an individual's behavior, and that when there is an opportunity to act, intention leads to action. The first element of the TRA attitude toward behavior is "the degree to which a person has a favorable or unfavorable evaluation or appraisal of the behavior in question" (Ajzen, 1991, p. 188). The subjective norm ( $\mathrm{SN})$ is the model's second component referred to as "the perceived social pressure to perform or not to perform the behavior" (Ajzen, 1991, p. 188). The TPB is similar to the TRA, but it includes an additional component, PerceivedBehavioral Control (PBC).PBC is defined as "the perceived ease or difficulty of performing the behavior" (Ajzen, 1991, p. 188).

In Bandura's Social Cognitive theory of moral agency, personal elements such as moral thought and self-evaluative reactions, moral behavior, and environmental forces interact as interacting determinants. In a later study, he stated that the theory identifies individuals' ability to exert a certain degree of control over their actions and subsequent environmental occurrences (Bandura, 2001). As a result, self-regulatory mechanisms exert control over the moral agency. Moral behavior is governed by 
social and personal sanctions. Self-sanctions function through self-condemning reactions to an individual's transgression, whereas social sanctions are based on the dread of external punishment. In terms of moral standards, self-sanctions are the primary guide that keeps behavior in check.

\subsection{Attitude of Eco-Spirituality (AEC)}

Several measures, including the Ecology Scale, Environmental Concern Scale, and New Environmental Paradigm (NEP) Scale, were used in studies in the domain of environmental well-being to further develop the attitude.Suganthi (2019) later devised an eco-spirituality scale, defining ecospirituality as "Having a reverential attitude toward the environment in taking care of it while dwelling within its premises" (Suganthi, 2019, p.110) which would be considered under the present study in incorporating spirituality to TPB.

Furthermore, only a few studies have found that attitude influences the link between environmental concern and environmental behavior intention (Chen \& Tung, 2014; Jang et al., 2015). In addition, literature supports the idea that attitude can mediate the relationship between environmental knowledge and environmental behavior intention (Kumar et al., 2017). As a result, the following hypotheses were proposed:

H1: Young educated consumer's attitude of ecospirituality has a significant impact on the sustainable consumption intention

H8: Attitude of eco-spirituality mediates the relationship between environmental concern and sustainable consumption intention

H9: Attitude of eco-spirituality mediates the relationship between environmental knowledge and sustainable consumption intention

\subsection{Subjective Norms (SN) and Perceived Behavioral Control (PBC)}

According to the theory of planned behavior, which was discussed prior, it consists of three components: attitude, subjective norms, and perceived behavioral control. The theory of planned behavior has proved effective in the prediction of intention toward a wide range of pro-environmental areas, indicating its application and relevance to the current study, according to studies conducted in the domain of environmental well-being (Chen \& Tung, 2014; Han et al., 2010).Subjective norms and perceived behavioral control, in particular, have been shown to have a major impact on the intention to engage in green and environmentally friendly actions in research (Han et al., 2010). As a result, the following hypotheses were developed:

$\mathrm{H} 2$ : Subjective norm has a significant influence on the sustainable consumption intention

\section{ISSN 2455-6378}

H3: Perceived behavioral control has a significant influence on the sustainable consumption intention

\subsection{Environmental Concern (EC) and \\ Knowledge (EK)}

Environmental concern, according to Dunlap and Jones (2002), is "the degree to which people are aware of environmental problems, support attempts to solve them, and/or demonstrate a readiness to contribute directly to their solution" (p. 485). Environmental concern has a major impact on attitudes toward eco-friendly products and services, according to previous research (Aman et al., 2012; Han et al., 2010; Hartmann \&Apaolaza-Ibanez, 2012). Furthermore, there is evidence that environmental concerns have a major impact on the intention to engage in ecologically responsible activities (Hartmann \&Apaolaza-Ibanez, 2012; Mostafa, 2009; Sang \&Bekhet, 2015). Hence, the following hypotheses were proposed;

H4: Environmental concern of young educated consumers significantly influences the attitude of eco-spirituality

H5: Environmental concern of young educated consumers significantly influences sustainable consumption intention

Fryxell and Lo (2003) have defined environmental knowledge as "what people know about environment, key relationship leading to environmental impact and collective responsibilities of individual necessary for sustainable development" (p.48). Previous research has discovered that environmental knowledge has a substantial impact on a consumer's attitude toward ecologically responsible conduct (Aman et al., 2012; Barber et al., 2009; Chan, 2001; Flamm, 2009). Furthermore, it has been scientifically demonstrated that environmental knowledge has a major impact on consumer intention and behavior toward ecologically friendly consumption (Kumar et al., 2017). As a result, environmental knowledge is likely to influence eco-spirituality and sustainable consumption intentions. As a result, the following hypotheses were proposed:

H6: Environmental concern of young educated consumers significantly influences the attitude of eco-spirituality

H7: Environmental knowledge of young educated consumers significantly influences sustainable consumption intention

The conceptual framework was established as indicated in Figure 1 based on the conceptualization of the constructs that would be considered for the study as mentioned above. 


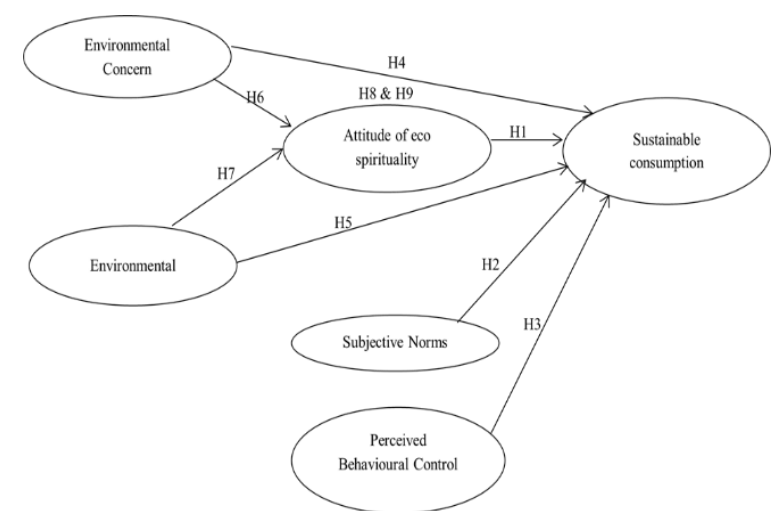

Figure 1: Conceptual Framework

\section{Materials and Methods}

At the commencement, 400 structured selfadministered

questionnaires

(Colombage\&Galahitiyawe, 2020) were personally delivered in the survey among young educated consumers in the Colombo area, from which 378 questionnaires were collected, yielding an effective response rate of 94.5 percent. The survey was conducted with a convenience sample, in keeping with the premise that non-probability sampling methods might be utilized if a sampling framework was not available (Saunders et al., 2019). EC (05 items), AEC comprised of five dimensions as Dwelling (05 items), Caring (05 items), Revering (04 items), Experiencing (03 items), Relating (03 items), SN (03 items), and PBC (03 items) were measured using a seven-point Likert type scale stretching from 1 - Strongly Disagree to 7 - Strongly Agree developed by Mostafa (2009), Suganthi (2020) and Kim and Han (2010) respectively. SCI (03 items) and EK (03 items) were operationalized using a fivepoint Likert-type scale ranging from 1 - Strongly Disagree to 5 - Strongly Agree developed by Wang et al. (2014) and Sidique et al. (2010) as cited in Kumar et al. (2017) respectively.

Outliers and missing values were first addressed using IBM SPSS 21.0 software (Galahitiyawe\& Jayakody, 2019), then multivariate assumptions were examined as proposed by Hair et al (2019). Bias tests were performed using Harman's Single Factor approach (Podsakoff et al., 2003) and the One-way ANOVA test, which revealed that common method bias and non-response bias were not present. The Structural Equation Modelling (SEM) was carried out with the confirmation of multivariate assumptions using the Analysis of Moment Structures (AMOS) 20.0 statistical analysis software. The study established discriminant validity (Fornell\&Larcker, 1981) and reliability by validating the threshold levels, whereas convergent validity was confirmed by factor loadings exceeding 0.7 . (Hair et al., 2019).

\section{Results and Discussion}

The structural model (CMIN/DF-2.618; GFI-0.873; RMSEA-0.083)established reflected path significance revealing $\operatorname{AEC}(\beta=0.462$, Pvalue $=0.000), \quad \mathrm{SN}(\beta=0.231, \quad \mathrm{P}$-value $=0.000)$, $\operatorname{PBC}(\beta=0.453, \quad \mathrm{P}$-value $=0.000), \quad \mathrm{EC}(\beta=0.321, \quad \mathrm{P}-$ value $=0.000)$ and $\operatorname{EK}(\beta=0.365$, $P$-value $=0.000)$ with statistically significant impact on SCI while EC $(\beta=0.436, \quad \mathrm{P}$-value $=0.000)$ and $\quad \mathrm{EK}(\beta=0.412, \quad \mathrm{P}$ value $=0.000)$ was revealed with a significant impact on AEC supporting $\mathrm{H} 1$ to $\mathrm{H} 7$ at $5 \%$ level of significance.

The mediating effect of AEC was tested using the bootstrap test whereboth direct (impact of EC on SCI $(\beta=0.332$, P-value $=0.001)$ and EK on SCI $(\beta=0.356$, $\mathrm{P}$-value $=0.001)$ ) and indirect paths (the impact of EC through AEC on SCI $(\beta=0.548, \mathrm{P}$-value $=0.000$ and EK through AEC on SCI $(\beta=0.556, \mathrm{P}$-value $=0.000))$ were significant at $10 \%$ confidence level revealing a partial mediation from AEC on the impact from EC and EK on SCI supporting $\mathrm{H} 8$ and H9. However, since the beta value of the indirect paths ishigher than that of the direct paths, it can be concluded that the total impact of EC and EK on SCI is higher when the impact fromEC and EKon SCI is mediated by AEC.

The results of the study suggest that young educated consumers having AEC tend to have a higher likelihood for SCI whichcomplements with Chan (2001) reflecting that an individual's attitudes are shaped by the cognitive assessment of the significance of consumption practices towards sustainability. Kim and Han (2010) complement the fact that an individual having control of skills, resources, and efficacy towards the intended behavior supported by social pressures from peers and family, behavior has more propensity to occur which supports the current study reflecting a young educated consumer with PBC and SN have a higher likelihood for SCI. The revealed partial mediation of AEC on the impact from EC and EK on SCI is supported by prior literature stating spirituality creates new trends in consumers driving them towards sustainable practices (Hunting \& Conroy, 2018). Therefore, overall, a young educated consumer with AEC having an EC and EK are more likely to engage in sustainable practices leading to a better environment around them for themselves and others.

\section{Conclusions}

In conclusion, the present research had significant theoretical implications enhancing the prediction power of TPB with the incorporation of the attitude of eco-spirituality and environment concern and environment knowledge. This leads tothe importance of integrating eco-spirituality initiativesin driving 
individuals towards sustainable consumptions practices. Finally, the current study paved the way for future research by allowing for the investigation of other psychological aspects in various samples and circumstances.

\section{Acknowledgments}

The authors would like to express their gratitude to their families, friends, and respondents for their assistance in completing this study.

\section{Reference}

[1] Ajzen, I. (1985). From intentions to actions: A theory of planned behavior. In J. Kuhl \& J. Beckmann (Eds.), Action Control. Springer. https://doi.org/https://doi.org/10.1007/978-3642-69746-3_2

[2] Ajzen, Icek. (1991). Theory of planned behavior. Organizational Behavior and Human Decision Processes, $\quad 50, \quad 179-211$. https://doi.org/10.1080/10410236.2018.1493416

[3] Bandura, A. (1991). Social cognitive theory of moral thought and action. In W. M. Kurtines \& J. L. Gewirtz (Eds.), Handbook of Moral Behavior and Development. Theory, Research and Applications (pp. 71-129). Hillsdale.

[4] Bandura, Albert. (2001). Social Cognitive Theory of Mass Communication. Media Psychology, 3(3), 265-299. https://doi.org/10.1207/S1532785XMEP0303_03

[5] Barber, N. A., \& Deale, C. (2014). Tapping Mindfulness to Shape Hotel Guests' Sustainable Behavior. Cornell Hospitality Quarterly, 55(1), 100-114. https://doi.org/10.1177/1938965513496315

[6] Barber, N., Taylor, C., \& Strick, S. (2009). Wine consumers' environmental knowledge and attitudes: Influence on willingness to purchase. International Journal of Wine Research, 1(1), 59-72. https://doi.org/10.2147/IJWR.S4649

[7] Brown, K. W., \& Ryan, R. M. (2003). The Benefits of Being Present: Mindfulness and Its Role in Psychological Well-Being. Journal of Personality and Social Psychology, 84(4), 822848. https://doi.org/10.1037/0022-3514.84.4.822

[8] Chan, R. Y. K. (2001). Determinants of Chinese Consumers ' Green Purchase Determinants of Chinese Consumers ' Green Purchase Behavior. Psychology \&Marketing, 18(4), 389-413.

[9] Chen, M. F., \& Tung, P. J. (2014). Developing an extended Theory of Planned Behavior model to predict consumers' intention to visit green hotels. International Journal of Hospitality Management, $\quad 36, \quad 221-230$. https://doi.org/10.1016/j.ijhm.2013.09.006

\section{ISSN 2455-6378}

[10] Colombage, V. K., \& Galahitiyawe, N. W. K. (2020). Basic Human Values and Customer Perceived Values Towards Green Purchase Intention. Sri Lankan Journal of Management, 25(1), 1-32.

[11] Dunlap, R., \& Jones, R. (2002). Environmental concern: Conceptual and measurement issues. In R. Dunlap \& W. Michelson (Eds.), Handbook of environmental sociology. Greenwood Press.

[12] Flamm, B. (2009). The impacts of environmental knowledge and attitudes on vehicle ownership and use. Transportation Research Part D: Transport and Environment, 14(4), 272-279. https://doi.org/10.1016/j.trd.2009.02.003

[13] Fornell, C., \& Larcker, D. F. (1981). Evaluating Structural Equation Models with Unobservable Variables and Measurement Error. 18(1), 39-50.

[14] Galahitiyawe, N. W. K., \& Jayakody, J. A. R. (2019). Managing Product Complexity and Variety for Operational Performance through an Integrated Green Supply Chain. Colombo Business Journal, 10(1), 19-43. https://doi.org/10.4038/cbj.v10i1.40

[15] Gethin, R. (2011). On some definitions of mindfulness. Contemporary Buddhism, 12(1), 263-279.

https://doi.org/10.1080/14639947.2011.564843

[16] Hair, J. F., Risher, J. J., Sarstedt, M., \& Ringle, C. M. (2019). When to use and how to report the results of PLS-SEM. European Business Review, 31(1), 2-24. https://doi.org/10.1108/EBR-112018-0203

[17] Han, H., Hsu, L. T. (Jane), \& Sheu, C. (2010). Application of the Theory of Planned Behavior to green hotel choice: Testing the effect of environmental friendly activities. Tourism Management, 31(3), 325-334. https://doi.org/10.1016/j.tourman.2009.03.013

[18] Hartmann, P., \& Apaolaza-Ibáñez, V. (2012). Consumer attitude and purchase intention toward green energy brands: The roles of psychological benefits and environmental concern. Journal of Business Research, 65(9), 1254-1263. https://doi.org/10.1016/j.jbusres.2011.11.001

[19] Hunting, A., \& Conroy, D. (2018). Spirituality, stewardship and consumption: new ways of living in a material world. Social Responsibility Journal, $\quad$ 14(2), 255-273. https://doi.org/10.1108/SRJ-06-2016-0097

[20] Jang, S. Y., Chung, J. Y., \& Kim, Y. G. (2015). Effects of Environmentally Friendly Perceptions on Customers' Intentions to Visit Environmentally Friendly Restaurants: An Extended Theory of Planned Behavior. Asia Pacific Journal of Tourism Research, 20(6), 599-618.

https://doi.org/10.1080/10941665.2014.923923 
[21] Katupotha, J. (2018). Islands of Sri Lanka. Wildlanka, 6(4), 176-212.

[22] Kim, Y., \& Han, H. (2010). Intention to pay conventional-hotel prices at a green hotel - a modification of the theory of planned behavior. Journal of Sustainable Tourism, 18(8), 9971014. https://doi.org/10.1080/09669582.2010.490300

[23] Kumar, B., Manrai, A. K., \& Manrai, L. A. (2017). Purchasing behaviour for environmentally sustainable products: A conceptual framework and empirical study. Journal of Retailing and Consumer Services, 34(February 2016), 1-9. https://doi.org/10.1016/j.jretconser.2016.09.004

[24] Milne, G. R., Villarroel Ordenes, F., \& Kaplan, B. (2020). Mindful consumption: Three consumer segment views. Australasian Marketing Journal, 28(1), 3-10. https://doi.org/10.1016/j.ausmj.2019.09.003

[25] Mostafa, M. M. (2009). Shades of green: A psychographic segmentation of the green consumer in Kuwait using self-organizing maps. Expert Systems with Applications, 36(8), 1103011038.

https://doi.org/10.1016/j.eswa.2009.02.088

[26] Pargament, K. I. (1999). The Psychology of Religion and Spirituality? Yes and No. International Journal for the Psychology of Religion, 9(1), 3-16.

[27] Podsakoff, P. M., MacKenzie, S. B., Lee, J. Y., \& Podsakoff, N. P. (2003). Common Method Biases in Behavioral Research: A Critical Review of the Literature and Recommended Remedies. Journal of Applied Psychology, 88(5), 879-903. https://doi.org/10.1037/00219010.88.5.879

[28] Sang, Y. N., \& Bekhet, H. A. (2015). Modelling electric vehicle usage intentions: An empirical

\section{ISSN 2455-6378}

study in Malaysia. Journal of Cleaner Production, 92, 75-83. https://doi.org/10.1016/j.jclepro.2014.12.045

[29] Saunders, M. N., Lewis, P., \& Thornhill, A. (2019). Research Methods For Business Students (8th ed.). Pearson Education Limited.

[30] Sheth, J. N., Sethia, N. K., \& Srinivas, S. (2011). Mindful consumption: A customer-centric approach to sustainability. Journal of the Academy of Marketing Science, 39(1), 21-39. https://doi.org/10.1007/s11747-010-0216-3

[31] Sidique, S. F., Joshi, S. V., \& Lupi, F. (2010). Factors influencing the rate of recycling: An analysis of Minnesota counties. Resources, Conservation and Recycling, 54(4), 242-249. https://doi.org/10.1016/j.resconrec.2009.08.006

[32] Suganthi, L. (2019). Ecospirituality: A Scale to Measure an Individual's Reverential Respect for the Environment. Ecopsychology, 11(2), 110122. https://doi.org/10.1089/eco.2018.0065

[33] Suganthi, L. (2020). Ecospirituality for organizational sustainability: An empirical study. Journal of Cleaner Production, 266, 121849. https://doi.org/10.1016/j.jclepro.2020.121849

[34] Ulluwishewa, R. (2018). Education in human values: Planting the seed of sustainability in young minds. In S. Dhiman \& J. Marques (Eds.), Handbook of Engaged Sustainability (Vols. 1-2, pp. 405-426). Springer International Publishing. https://doi.org/10.1007/978-3-319-71312-0_23

[35] Wang, P., Liu, Q., \& Qi, Y. (2014). Factors influencing sustainable consumption behaviors: A survey of the rural residents in China. Journal of Cleaner Production, 63, 152-165. https://doi.org/10.1016/j.jclepro.2013.05.007

[36] Wood, R., \& Bandura, A. (1989). Social Cognitive Theory of Organizational Management. The Academy of Management Review, 14(3), 361-384. 